\title{
Building a Database for Soil Tests and judging their Validity as Road Construction Materials
}

\author{
Thowaiba Elawad Hagali Ahmed \\ Imam Abdulrahman Bin Faisal University (University of Dammam) \\ Faculty of Education-Jubail-Computer Science Department
}

\begin{abstract}
This study aims at building a database of soil and materials tests to use them as materials for construction of roads. The results of the tests will be used to write the materials reports to identify the soil resistance and judging whether or not suitable for use as road construction materials. If they are not valid for the purpose then other materials could be used and provide the required alternative of these materials or made the necessary treatment. The database has been developed through the Oracle database management system which is considered as the strong database system for it provided the management with the necessary work information by transferring them into practical databases which will be used in decision making process and monitoring the work performance in order to finalize the work in the quickest possible way. The oracle also provided the suitable amount of security for the sensitive practical laboratory information. The program could be executed in any computer having an Oracle database (SQL \& Developer) or Developer program only if the program works on client/server system.
\end{abstract}

\section{Keywords}

Database, Soil Tests, Oracle, Sudan.

\section{INTRODUCTION}

It is understood that the cultural, social and economic revival is closely associated in its all respects with the extent of unity and coherence of any one country, a matter requiring one common link to nurse all these directions and contribute directly in security of the social life and activate the commercial activity and conveyance of thoughts and beliefs for more coherence and cross-fertilizations of thoughts and beliefs.

Since the ancient times, the construction roads, although they are costly, represent and answer so many questions which are not learnt or heard by the ordinary man, but they leave great impacts in his soul and provide the ordinary man with information which has never think of it. The importance of the paved roads are summed up, but not limited to, the following: Realizing security, abundance and prosperity, help in cultural interaction and realization of national unity,

help in political stability, help in social change, employment of labors and facilitation of services, increase of national income and Increase of per capita income and economic and social growth in the country and assist in opening new markets help in developments of brotherly relationships between peoples and flourishing of trade, imports and exports fast. For the importance of roads and industry of roads, the soil shall be good for construction of a road in standard specifications by conducting so many fields and lab tests in order to identify the soil resistance, specifications and to decide to what extent the soil is good for use as material for construction of roads. Here we intend to create a database to conduct soil and aggregate as materials for pavement of roads which will be used by the National Highway Authority in Sudan.

\section{RESEARCH PROBLEM}

The study raised some questions which represent the core problems of the research which summed up in answering these questions:

- What are the benefits of using databases in laboratory experiments?

- Does this technology provide sufficient security for sensitive laboratory data?

- Why the use of database software techniques in this area is lagging behind the use of these technologies in other areas for a long time.

\section{RESEARCH OBJECTIVES}

The main objective of the study is to build a database of soil tests and the judgment of their validity to build roads in addition to other goals:

- Identifying the resistance and specifications of the soil.

- Use of test results in writing the report of materials which is considered as part of contract documents with any company working in roads construction fields.

- The results and reports will be used in constructional design so that if the materials are found to be as required, then other alternatives will be checked and provide the necessary substitute of these materials or treat them.

Keeping and analyzing and easy retrieval of information in order use it in the field of development of researches and studies.

\section{STEPS OF SOIL TESTS [1]}

Here we'll take a quick look about steps of soil tests after surveying a number of technicians and field engineers.

\section{4-1 Office Work:}

Collection of available information about the site from local official authorities such as topographical maps, aerial and space pictures and other information about the previous use of the site (quarries, mines, waste landfill, wells etc) as well as laws, rules and requirements for establishment of roads in the area.

In case there are any studies about the soil in the surrounding sites, they should be obtaining as well as collection of information about the condition of the existing buildings particularly if they are in deteriorated state due to the underground water or any other relevant information in relation with the site. 


\section{4-2 Field works:}

The entire site shall be inspected carefully and locating all natural phenomenon in order to lay down the required work test schedule as regards determining the need for conducting initial tests, work methods and tests which will be conducted and sampling process, making a survey map for the soil topography, matching of geological maps and observing the phenomena found in the site such as swamps and ponds, surface residues, valleys etc since these site may require additional tests in order to know whether some land piles have been added to the site or whether some land layers have been removed in order to study the pre-merger of land layers and observing the technical problems occurred at the site and surrounding sites.

\section{4-3 Geophysical Studies:}

The geophysical studies are considered as very important studies supporting the digging works. There are two methods through which you can initially identify different layers of the land and depths of ground water level which are: The Seismic and Natural Resistivity. The two methods are summed up in sending vibrant waves in the soil and receive these ways by geophones from pre-determined location. The waves are made by dropping a hammer on a metal base fixed on the surface of the land. The flow speed of the sound waves penetrating the land layers are measured by a machine connected with the geophones. The density and thickness of the land layers could be determined by analyzing information as well as determining the geometrical factors. These studies are very important in studying the caves inside the rocks or determining the locations and depth of the rocks under land layers.

\section{4-4 Digging Works (Soil Borings)}

The borings are ground diggings in the site to be explored in different depth through which we can obtain soil samples in order to identify the type, and order of the substrates. The digging could be made by hand or any helpful machine.

\section{4-5 Preparation and Sample Quantity:}

The soil is prepared for making necessary lab test according to sampling method [2]. The quantity of samples depends on the types and number of tests. It is better to take sufficient samples according to the requirement of standard specifications in order to conduct other necessary lab tests on the soil according to requirements. Each sample will be analyzed separately in order to determine the variance of soil characteristics.

\section{ANALYSIS}

The system analysis means return the system to its primary units before studying of these units in order to list the weakness points and identify the requirements of the new information system [3]. The researcher has conducted a detailed study of the current system by collecting the required information from the engineers and technicians working at the Soil Laboratory of the National Roads \& Bridges Authority in Sudan. The researcher revealed that the current testing method, which is based on MS Excel software plus the normal calculator, is a waste of time and effort, so that the researcher confirmed the necessity of finding out another method based on the computerized database system enabling the user to conduct the required operation easily and in the next paragraphs the researcher reviews samples of tests conducted at the National Highway Authority laboratory. [4], [5] ,[6].

\section{5-1 Water Content:}

The Water Content "WC" in the cohesive soil of the samples extracted from test borings is determined accordingly in order to know water contents in the natural soil and conduct the necessary tests for determining the liquidity limit (LL) and Plasticity Limit (PL) used in the classification of soil. Determining the water content is considered as one of the essential requirements of the soil reports. The normal humidity rate in the sand and aggregate soil ranges between 15\%-20\% while the water contents in the muddy and slit (alluvium) is ranging between $80-15 \%$ but the WC rate may reach $500 \%$ in the organic soil.

\section{5-2 Atterberg Limit:}

The Swedish scientist Atterberg determined four elements of soil cohesion which are liquidity, cohesion, semi-solid and soil element and consider the limit between liquidity and plasticity is Liquid Limit and Plastic Limit and the limit between the plasticity and semi-solidness is Plastic Limit and the semi-solid limit. He furthermore determined the limit separating the solid and semi-solid limit is Shrinkage Limit (SL). After determining these limits by routine test using the specialized tests, so it is necessary to find the Plasticity Index (PI) which is used in identifying the soil behavior as well as in the linkage equations for soil bearing strength and to know whether the type of swelling and collapsible soils. The liquidity index $=$ (WC-Pl) / (LL-PL) through which we can determine the Liquefaction of Soil (SL) when the Liquidity Limit is more than (1) $(\mathrm{LL}>1)$.

\section{5-3 Grain Size Distribution (Sieve Analysis)}

The (mechanical) grain size distribution test is used in classification of soil through sieve analysis using sieves with opening ranging between $100 \mathrm{~mm}$ (4) to $0.75 \mathrm{~mm}$ No. 200 according to the American standards as mentioned in the following table and Hydrometer for the soil passing through drawing the grading curve which is used for determining of the rates of soil materials top of which clay materials.

\section{5-4 Compaction (Proctor) Test:}

The compaction test (relationship between the density and moisture) i.e determining the relationship between the dry weight unit of the soil (GD) and WC before determining the maximum dry unit weight and the Optimum Moisture Contents (OMC) using two methods according to Proctor Test in order to identify the soil compaction power in the laboratory test in order to apply on nature using the different compaction equipment. The current two compaction methods.

\section{5-5 California Bearing Ratio (CBR)}

The CBR is conducting a load penetration test in the laboratory by penetration of certain metal rod of certain diameter in certain speed in the soil in order to identify the water content and density of the soil. The test will give information about the swelling level and the lost strength rate in the fully water saturated soil. The CBR also is used to identify the soil behavior under the asphalt base course (base materials). The test could be conducted in both field and laboratory.

\section{EXECUTION OF THE SYSTEM}

The system is executed by database management system "Oracle"[7],[8], [9] for the feature of the software "Oracle" which were mentioned in the foregoing "Study Abstract".

The developed Oracle system has so many interfaces which are: The main menu FIG(1), selected data entry screen FIG(2), Atterberg test screen FIG(3), California Bearing Ration screen FIG(4), field density selection screen FIG (5), water content selection screen FIG(6), sieve analysis selection screen FIG(7) \& Proctor test screen FIG(8).The system may extract the required report supporting the decision making such as 
mentioned in figures (9), (10), (11), (12), (13) since each test may be printed in a report submitted together with the sample report to the team who will execute the road.

We present hereunder the data entry screens of the system and the reports extracted from the system:

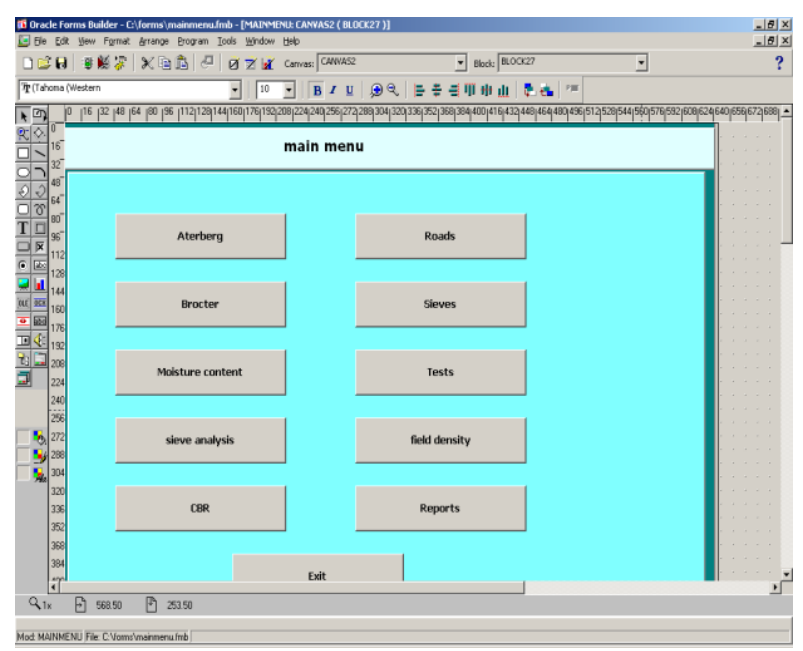

Fig. (1): Main System Screen

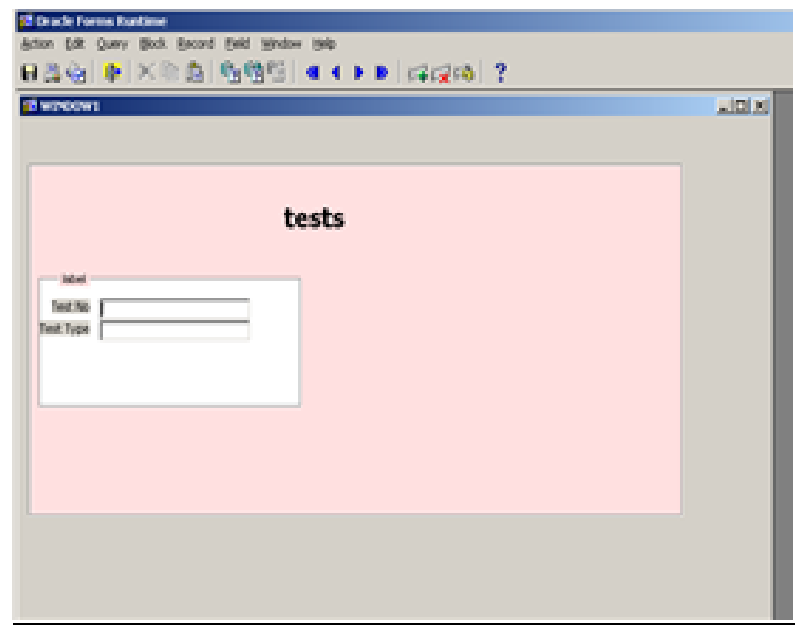

Fig (2): Type of Test Entry Screen

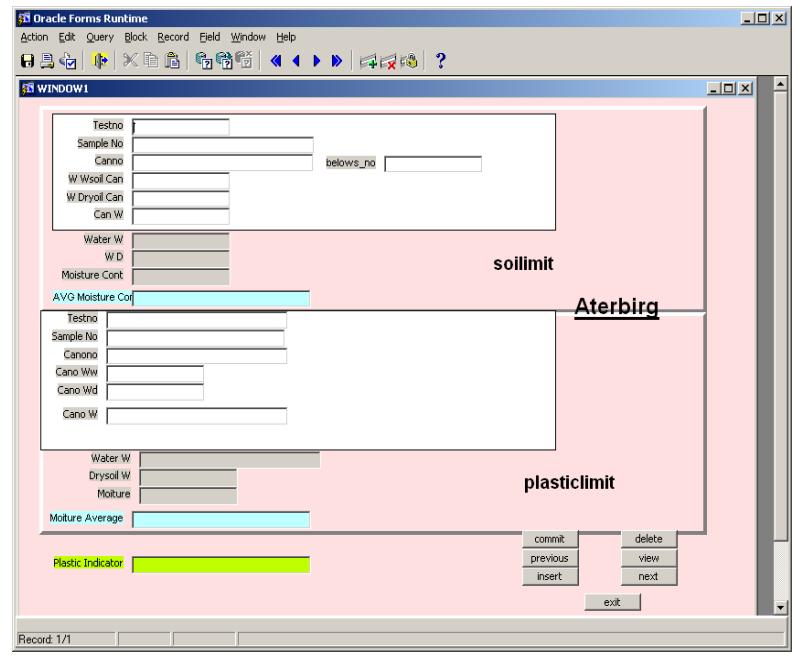

Fig. (3): Liquidity/Plasticity Limits selection Screen

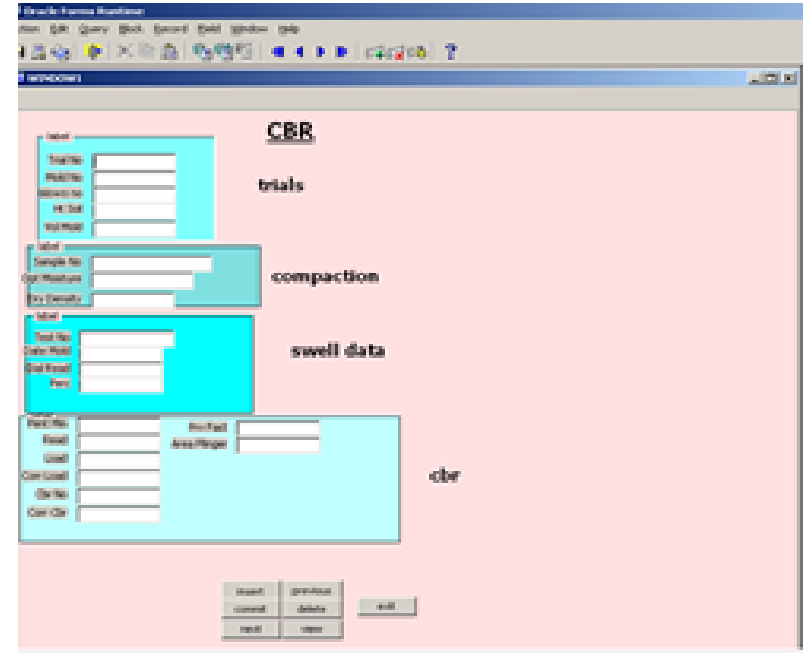

Fig. (4): CBR selection Screen

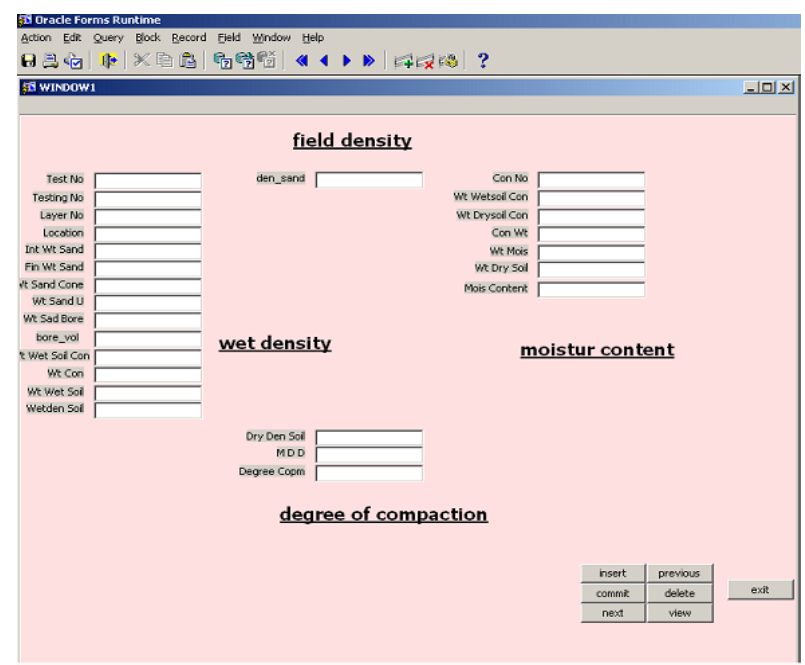

Fig. (5): Field Density selection Screen

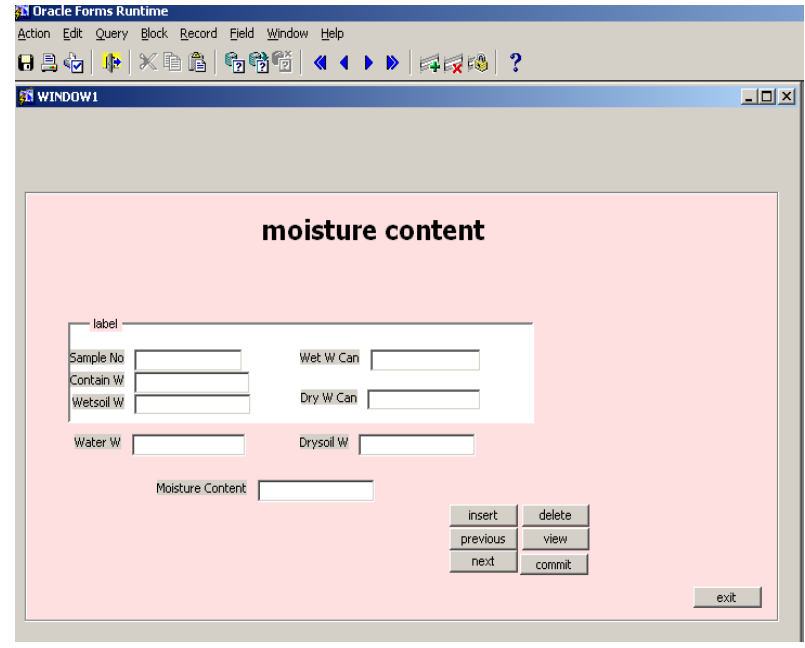

Fig. (6): Moisture Content selection Screen 


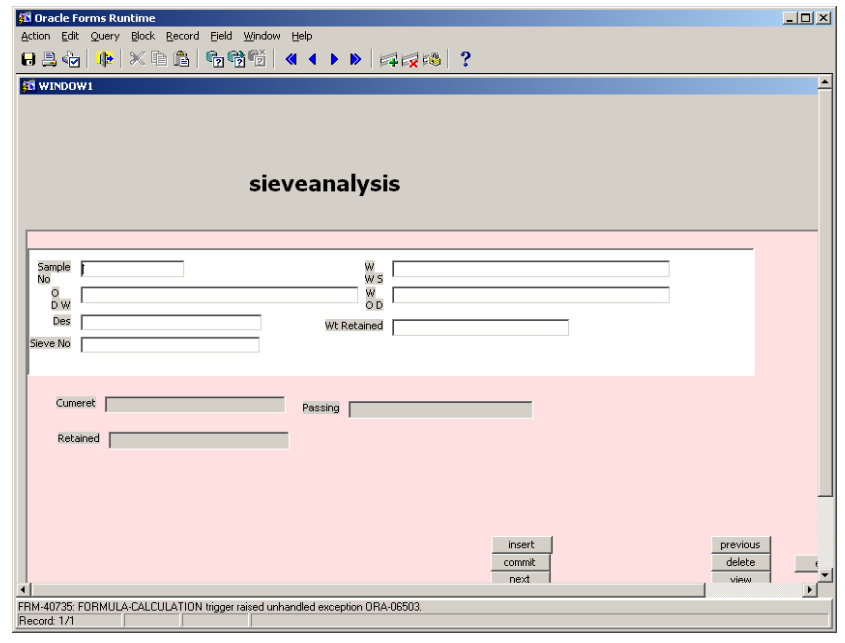

Fig. (7): Sieve Analysis Test Screen

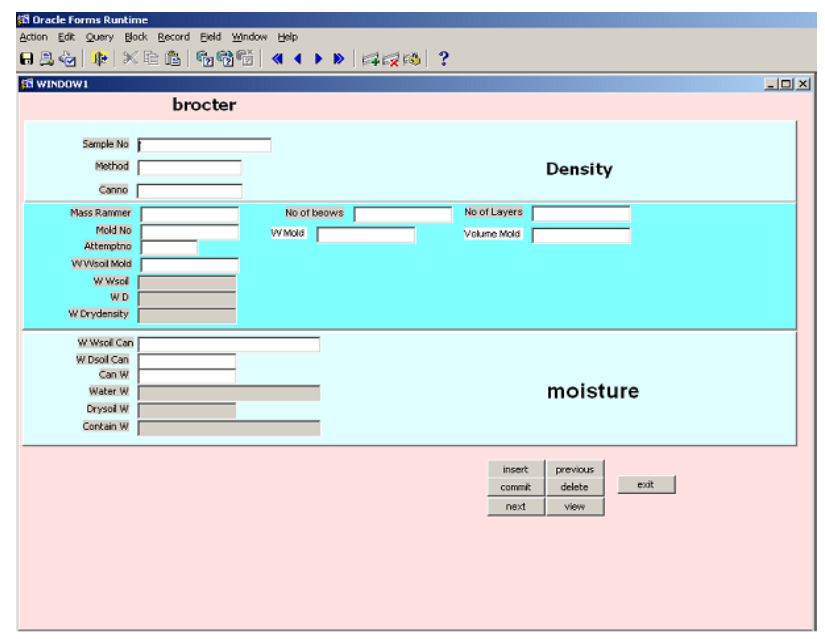

Fig. (8): Density \& Moisture Relation Test Screen

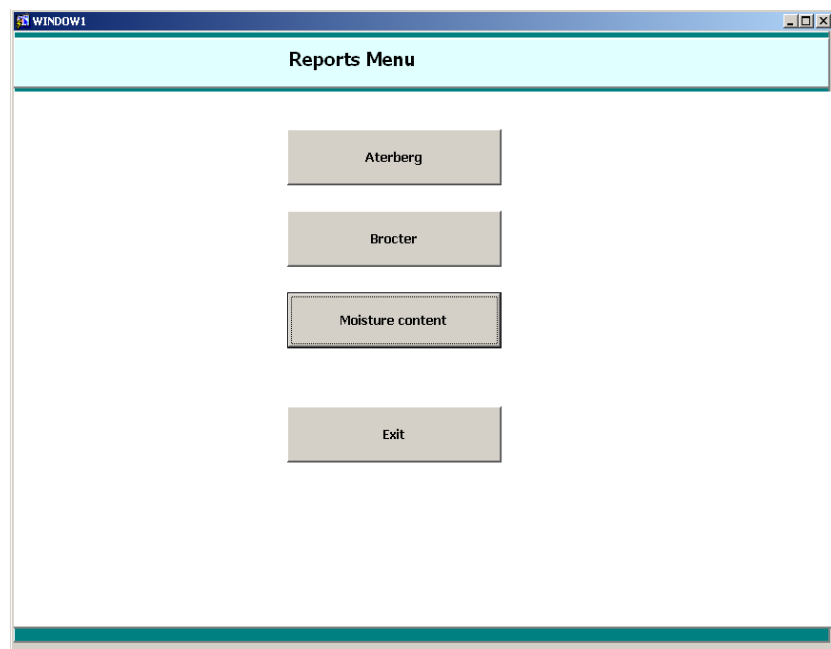

Fig. (9): Reports Extraction Screen

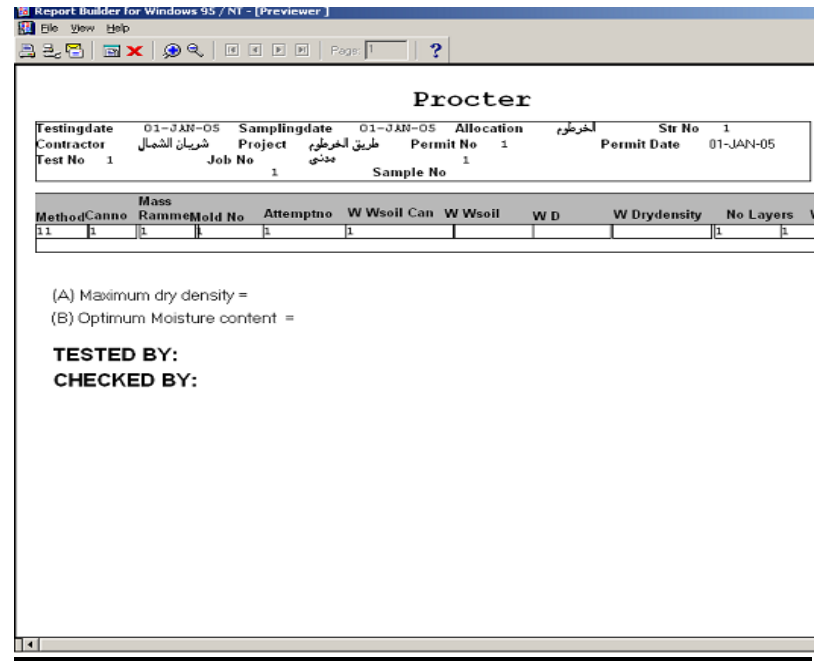

Fig. (10): Density \& Moisture Relation Report (Proctor)

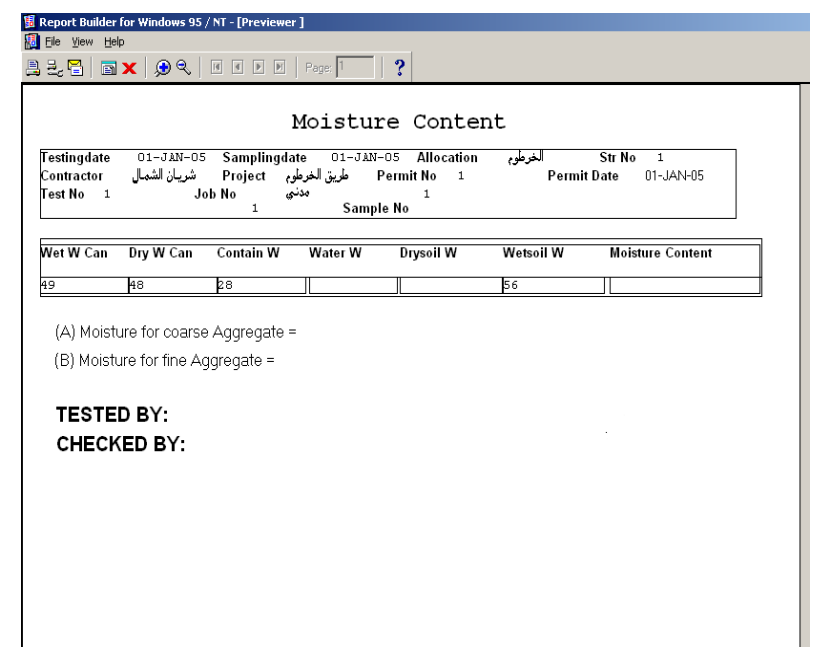

Fig. (11): Report on Moisture Content Test

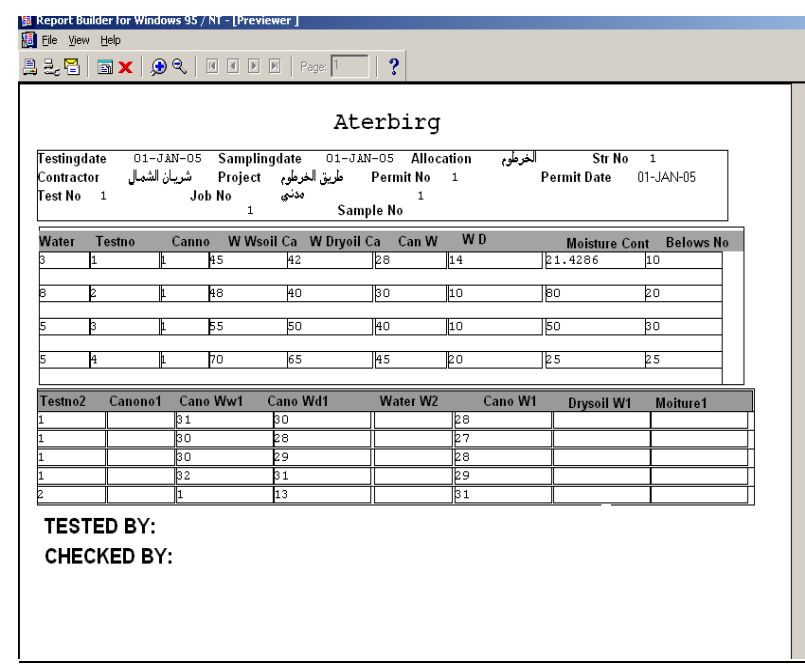

Fig. (12): Liquidity/ Plasticity Limits Test Report 


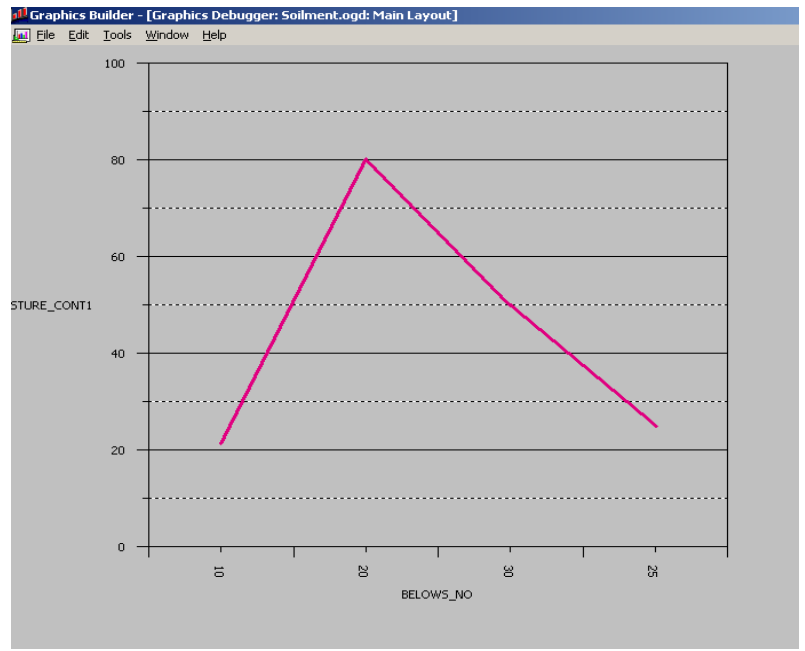

Fig. (13): A graph showing the relationship of hits numbers compare with moisture content

\section{RESEARCH RESULTS}

- The system has provided a high level security for the sensitive laboratory information.

- The system has facilitated the decision-making process, control of work performance, improvement of productivity and completion of work at the highest possible speed.

- The system saved the time and effort which compared with the old methods such as use of calculator and sometimes Excel program.

- Using the database management system -Oracle- has given the system many features such as portability, scalability flexibility and easy maintenance.

- This system can be applied wherever the sample is taken using a laptop computer on which the program is installed and uploaded.

\section{CONCLUSION AND RECOMMENDATIONS}

Therefore, this study tackles creation database of soil tests for National Highway Authority in Sudan and according to this study we recommended the following:

- Provision of tools necessary to apply the system at all branches of the National Roads and Bridges Authority in Sudan such as (computers, transportation, cables and switches) according to the required volume of work.
- Training of the staff on the system until they master how to implement the system efficiently.

- The system can be developed by development of the network, for example, using the wireless network system so that the system becomes more flexible saving much effort and time.

- This program can also be developed by developing the materials map in the Sudan using GIS in order to benefit from this system in the field of researches.

\section{ACKNOWLEDGMENTS}

Thanks and appreciations are due to: the National Highway Authority in Sudan for providing the data, advice and support all over the period of this study.

\section{REFERENCES}

[1] Soil Survey Staff- Soil Survey Field and Laboratory Methods Manual. Soil Survey Investigations Report2014- No. 51, Version 2.0. R. Burt and Soil Survey Staff (ed.). U.S. Department of Agriculture, Natural Resources Conservation Service.

[2] James L. Walworth - Soil Sampling and Analysis-Arizona Cooperative Extension-2006-university of Arizona

[3] Jeffrey A. Hoffer- Joey George (Author), Joseph S. Valacich- Modern Systems Analysis and Design--7 EDITION-2014-Pearson.

[4] Md Gazi Ferooz Rahman- MDH Talukder- AHMM Rahman -Assessment of Soil Compaction - A Project Study-2011- -MIST Journal GALAXY (DHAKA)

[5] Muhammad Bhatti - A Few Tests for Highway Materials and Construction / Rehabilitationhttps://www.linkedin.com/pulse/20141125102658112545392-a-few-tests-for-highway-materials-andconstruction-rehabilitation-2014-(acssed 17.01.15).

[6] American ASTM standard volume4.09 rocks and soils2016-standard by ASTM international

[7] Kevin Loney - Oracle Database11G the complete references-2009- McGraw-Hill Companies.

[8] Ramez Elmasri, Shamkant B. Navathe- Fundamental of database systems-2010- Addison-Wesley, sixth edition.

[9] Lance Ashdown, Tom Kyte, Oracle Database Concepts, 11g Release 2 (11.2) MAY 2014. 